Firmness of adipose tissues is of primary importance. During the last few years, several factors (selection, slaughter of light pigs, feeding) have led to a deterioration in this quality. Water and C18:2 contents on the one hand, protein and C18:0 contents on the other hand are respectively and positively correlated with firmness. Beside hem pigments, carotenoids are involved in the colour of these tissues. Flavour is affected by the presence of steroids and of $5 \alpha$-androstenone, in particular. It is also affected by some fat-soluble components. The processing ability of adipose tissues into dry products requires a high firmness, i.e. tissues with a high protein and saturated fatty acid content and a low water content.

In animal production, two factors have a major influence on tissue composition : feeding, since the C18:2 content may vary from $8-32$ p. 100 according to the nature of the diet and second, the breed, since adipose tissues issued from double-muscled breeds are characterized by a high water content (up to $30 \mathrm{p} .100$ in backfat). Processed products include $20-50 \mathrm{p} .100$ fatty tissues. The particle size of fat in ground meat products vary from several $\mathrm{mm}$ to some microns according as to whether there are adipocyte clusters or lipids liberated from their membrane. Their absorption in the digestive transit is thus more or less easy. Beside their high lipid content, meat products also contain cholesterol in rather large amounts.

\title{
Lipids and qualities of pork adipose and muscular tissues. Factors of variation. 2nd Part: Lipids and qualities of muscle tissues. Factors of variation
}

\author{
Josiane BOUT ${ }^{(1)}$, J.P. GIRARD ${ }^{(2)}$ \\ (1) Institut National de la Recherche Agronomique, Station de Recherches sur la Viande, \\ Theix 63122 Ceyrat \\ (2) Institut Technique du Porc, B.P. 3, 35650 Le Rheu
}

It has been established that lipids are involved in the determinism of meat quality. They have an effect on the aspect, colour, tenderness, juiciness and flavour of the meat.

As regards the latter quality, a basal quantity of lipids is required to the development of the species specific flavour. Lipids have also an effect on the processing ability. Processing of meat into high quality dry products require a higher lipid content of meat than for cooked products.

The breed seems to be the determining factor affecting the quantities and nature of lipids deposited in the muscle. At equal slaughter weights, the Longissimus dorsi from animals of the double-muscled breed contains more lipids than that of dual-purpose breeds (1.7 versus $1.2 \mathrm{~g} /$ $100 \mathrm{~g}$ of meat). Red muscles have also a higher lipid content than white ones. The other factors of variation are less important.

Fiom a nutritional point of view, pork is disregarded by most nutritionists. As a matter of fact, in most cases the lipid supply per $100 \mathrm{~g}$ of crude pork does not exceed 1.5 to $2.0 \mathrm{~g}$, i.e. $1 / 50$ of the daily amount recommended in most diets. The $\mathrm{P} / \mathrm{S}$ ratio (polyunsaturated fatty acids to saturated fatty acids) ranges around 0.3 and 0.4 which ranks pork lipids after beef and poultry meat in terms of risk of atherosclerosis occurrence. Moreover, the cholesterol supply per $100 \mathrm{~g}$ of pork does not exceed $50 \mathrm{mg}$. By contrast, meat products have a high lipid content : fatty acids and cholesterol. 